present concepts of immunity, respiration and other metabolic processes, there are inevitably sections in which over-condensation could lead to misconceptions, such as those dealing with the absorption of polypeptides and protein and the description of hypersensitivity. In general, however, the book is remarkably free of errors. But it is doubtful if Smyth is justified in describing the rapid maturation of Schistocephalus as "an adaptation undoubtedly related to the weak mode of attachment". Schistocephalus can maintain itself for more than seven days in a specific region of the intestine, so it is clearly as capable of combating peristalsis as are more conventional tapeworms equipped with hooks and suckers. The relatively short adult life is much more likely to be correlated with its inability to produce new, and discard old, tissue as do most tapeworms.

One might also suggest that the three chapters covering inflammatory and immunological responses are too heavily biased towards humoral responses and serological techniques for detecting circulating antibodies and that too little space is devoted to cell mediated responses, IgA and reagins, which in recent years have come to be so important in the interpretation of immune responses to nematodes.

But these are minor quibbles about what is a most useful book, no review of which would be complete without mention of the excellent chapter on in vitro cultivation of tapeworms. Nobody interested in cestode physiology should be without this book; students will be stimulated by the gaps in our knowledge which Smyth repeatedly emphasizes, and teachers will find much of value, not least many excellent clear line drawings. C. A. Hopkins

\section{INTERNATIONAL PHARMACOLOGY}

\section{Pharmacological Research Communications}

Vol. 1, Nos. 1 and 2. (Academic Press: London and New York, March, June 1969. Published for the Italian Pharmacological Society.) Vol. 1 (4 issues) 84s; $\$ 10$.

The rapid publication of important pharmacological results is becoming increasingly difficult and sometimes many months elapse before a paper appears in print. This new journal represents an attempt to fill the gap and at present this appears to be highly successful in these two parts of volume one. For example, in the March number the majority of papers were received for publication during the month of February. The list of editors is very impressive, guaranteeing a high standard of papers. Although this is an international journal, all the papers are in English. We owe a debt of gratitude to the Italian Pharmacological Society, which initiated the project and made the new journal its official publication (at the same time discontinuing publication of the Archivio Italiano di Pharmacologia), and to the Italian National Research Council for generous financial support.

The papers are reproduced directly from manuscripts, thus helping rapid publication. This means that the typed manuscripts must be free from blemishes, and a rapid perusal of the contents shows that this has been largely accomplished. At the same time, the typescript is pleasantly spaced without any overcrowding and is usually easy to read. The standard of English from such international contributions is remarkably high and if, occasionally, there is a slight flavour of the original language, this lends a little spice without detracting in any way from clear exposition.

The second part of volume one consists largely of the abstracts of the International Symposium on Bradykinin and Related Kinins held in Fiescole in July this year. The scientific standard of the papers and of the contributors is high and it gives me pleasure that the batting is opened by Heinz Schild with a neat and ingenious contribution.

\section{MUDDLED MIGRATION}

The Mystery of Animal Migration

By Matthicu Ricard. English version by Peter J. Whitehead. Pp. xiii $+209+16$ plates. (Constable: London, September 1969.) 45s.

THeRe have been so many popular books in this field that another could only be justified if it brought a new clarity of exposition, or at least a new approach. This book does neither. What would the intelligent layman make of the sentence, "He showed that an astronomical point, envisaged by a process of reasoning and deduction, would necessitate in the bird a physiological acuity of the senses, a concept difficult to comprehend"? Are we enlightened by the unelaborated remark, "Thanks to the very complex structure of their eyes, the bees are able to analyse polarized light in the sky and thus to navigate"? Again and again, concepts are muddled, experimental results misconstrued, spectacular claims over-emphasized. The text is padded out with unnecessary descriptions of specific bodily details or non-migratory activities, and flavoured with phrases like "symbol of untamed nature ... a breath of the wilds ... noble birds ... monarch of the seas".

As for originality, while mining of existing sources is acceptable, one would not expect the section on birds (occupying more than half the book) to be so very similar in layout, content and illustration to Jean Dorst's (much fuller and better) book The Migrations of Birds.

There are twelve very presentable black-and-white plates.

G. V. T. MatThews

\section{EVOLUTION OF AGRICULTURE}

The Domestication and Exploitation of Plants and Animals

Edited by Peter J. Ucko and G. W. Dimbleby. (Proceedings of a meeting of the Research Seminar in Archaeology and Related Subjects.) Pp. xxvi+581. (Duckworth: London, July 1969.) 147s.

IN addition to its preface, an introduction in two parts, and a conclusion, this volume contains forty-seven articles by forty-five authors. These vary in length from four to twenty-eight pages and in quality from slightly sophomoric to scholarly and distinguished.

The editors have, with some degree of success, organized the articles into five parts: origins of domestication; methods of investigation; regional and local evidence for domestication; studies of particular taxonomic groups; and human nutrition. In each of these categories there are one or more outstanding articles; I wish to review briefly several of these that I found to be of particular interest.

Discussing the ecological background of plant domestication, Hawkes emphasizes the role of weeds-now usually defined as intruders on disturbed habitats-in the evolution of cultivated plants. Such plants are by their nature "preadapted" to cultivation. To primitive man it may have seemed "little short of miraculous", Hawkes suggests, to find plants needed for food springing up around his habitation. Also emphasizing "weediness" and preadaptation, Zohary postulates that tho agricultural development of Western Asia was dependent on three cereals-einkorm wheat, emmer wheat, and tworowed barley. All of these have still existing wild forms which differ from the cultivated in having fragile, easily shattering heads and devices for forcing the fallen seeds into the soil. The modern bread wheats, which in their chromosome composition are hexaploids, have a genome derived from a weedy wild grass Aegilops squarrosa. Zohary attributes the wide adaptation of the bread wheats to the weediness of this parent.

Discussing early Near Eastern domestication, Flannery takes issue with the frequently cited notion that early agriculture gave rise to a "more stable" food supply. 